\title{
Research on Statistics Teaching Reform Based on Teachers' Attitude
}

\author{
Kangli Zhao ${ }^{1, a, *}$ Jianhua $\mathrm{Lu}^{2, \mathrm{~b}}$ and Guoxi Xue $\mathrm{X}^{2, \mathrm{c}}$ \\ ${ }^{1}$ School of Mathematics and Computer Science, Aba Teachers University, Aba, Sichuan, P.R.China, \\ ${ }^{2}$ School of Economics and Management, Aba Teachers University, Aba, Sichuan, P.R.China,

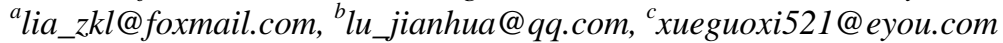 \\ *corresponding author
}

\begin{abstract}
As the promoters and implementers of curriculum reform, teachers have played a crucial role in the success of curriculum reform. The economics and management major is a profession closely related to real life. The statistical study of the major should be practical and professional. From the perspective of teacher attitude, this paper classifies teachers and discusses the characteristics of each category of teachers, so as to propose corresponding guidance methods to promote the success of statistical teaching reform.
\end{abstract}

Keywords: statistics, teaching reform, teachers'attitude, economics and management

\section{INTRODUCTION}

"Statistics" is a branch of applied mathematics and one of the ten courses required for the majors of economics and management specified by the Ministry of Education of China. Learning statistics helps students to better understand the overall quantitative and quantitative relationships of objective phenomena by collecting, collating, and analyzing data, helps them consolidating mathematics, economics, and drawing certain management conclusions from the data. In the Outline of the National Medium- and Long-Term Education Reform and Development Plan (2010-2020), the necessity of curriculum reform in the management of professional statistics is clearly put forward. At present, most of the research on statistical teaching reform is carried out from the aspects of teaching methods, teaching methods, teaching software, etc., but lacks attention to teachers' attitudes in educational reform. However, studies have shown that the promotion of education reform mainly depends on teachers' recognition of the necessity of education reform, the efficiency of reform and the sense of belonging[1]. Actually, education reform has indeed brought a lot of influence to teachers, for example, Top-down teaching reform often puts too much burden on teachers, and teachers sometimes even begin to doubt their own value[2,3] At the same time, teachers need to work hard to keep up with the changes of the times to adapt to the new role that education reform gives them[4]. Thus, how to support teachers in the new situation, help them to change roles and update skills, help teachers to better adapt to education reform, and improve enthusiasm and participation in teaching reform is the key to the success of teaching reform. From the teacher's point of view, combined with the characteristics of statistical teaching of economics and management major, as well as the main problems in the teaching process, from the attitude of teachers on teaching reform, this paper puts forward the suggestions for the teaching reform of economics and statistics major.

\section{PROBLEMS IN THE TEACHING OF STATISTICS IN ECONOMICS AND MANAGEMENT MAJOR}

\subsection{Outdated Teaching Methods, Lack of Practical Operation Curriculum Design}

Since statistics is a branch of applied mathematics, there are many mathematical formulas, theorems, and so on. In the teaching of statistics, teachers are mostly based on theory, the formula, theorem derivation and the logical thinking ability of mathematics are the key points for teachers to teach in class. However, for most general undergraduate colleges, the economics and management majors are often the arts and sciences, and the students' mathematics skills are different. At the same time, for the professional management, it is more important to study the socio-economic phenomenon by using statistical methods than to know the origin of various formulas and theorems in statistics. However, most of the general undergraduates major in economics and management do not have enough practical operation hours, but mainly classroom teaching[5].

\subsection{Teaching Materials can't Keep up with the Times}

The economics and management major is a profession that is closely integrated with the social economy. However, the social economy has changed rapidly, but the statistical textbooks of the economics and management majors have not kept pace with the times[6]. There are lack of statistical textbooks written for the requirements of the contemporary economic and management professions. Specifically, most of the current statistical textbooks for non-statistical majors are partial case-type, but these cases are outdated and cannot keep up with the times. At the same time, many cases are engineering cases instead of management cases, they are not 
easy to stimulate students' interest in learning.

\subsection{Lack of Case Teaching Combined with Professional Characteristics}

The case-study method was a teaching method proposed by Christopher Columbus Langdale, former dean of Harvard Law School. It was originally applied to legal education and was widely used in medicine, economics, management, and other disciplines. The case teaching method is very suitable for the teaching of statistics in economics and management. Specifically, the following three types of cases can be used in the teaching of statistical professional courses: 1) practical cases, 2) description cases, 3) analytical cases. These case teachings can enable students to improve their hands-on ability, combine their own real life to develop their own relevant cases of statistics, and use the knowledge they have learned to analyze cases using software. However, as far as the current statistical classroom teaching is concerned, the case teaching method has not fully entered the student classroom. The teaching of statistics is still based on teacher output and lacks student feedback.

\subsection{The Content of Teaching Reform is not Deep Enough and Teachers are Less Motivated}

At present, the statistical teaching reform for economics and management majors mainly focuses on teaching methods, teaching methods, and teaching software. In the implementation process, it is mainly to improve the syllabus, improve the teaching plan, and introduce relevant software as a means of reform. However, education and teaching is the process of interaction between teachers and students. All the implementers of teaching reform are teachers. The ultimate goal of the reform is to improve the skills and abilities of each student, narrow the gap between students and students, and output qualified talents for the country and society. The key factors for successful education reform are internal motivation, overall improvement of education level, teamwork, etc[7]. Therefore, paying attention to teaching methods and means, introducing teaching software, etc., although they can improve the teaching quality of economics and statistics of professional management to a certain extent, but cannot fundamentally reform the teaching of statistics, nor can it produce longer-term and larger scope influences.

\section{REFORM OF STATISTICS COURSES FOR ECONOMICS AND MANAGEMENT MAJORS BASED ON TEACHER'S ATTITUDE}

By analyzing the problems existing in the statistical teaching of economics and management, we can know that the focus of teaching reform lies in "people". As the recipient of knowledge, students are the judges to measure the results of teaching reform, while teachers as the disseminators of knowledge are the executors of teaching reform. The enthusiasm of teachers' teaching reform is directly related to the quality and achievements of teaching reform[8]. Therefore, according to the different attitudes of teachers towards teaching reform, the teachers are divided into four categories[9], and put forward corresponding suggestions for different types of teachers.

\subsection{Leading Teacher: Rational and Practical}

"Leading teachers" insist that the education system must undergo substantial changes, and firmly believe that the need for teaching reform has existed for many years, but has not been met. For the leading teachers, although the teaching reforms make them need to spend more time in teaching, this time expenditure is not the "slavery" of the school, but the time cost that must be paid to improve their skills. Leading teachers are more rational and more practical in their understanding of teaching reform. Leading teachers should be the central figure in the reform of statistics teaching. Because such teachers have a high degree of reform enthusiasm, a clear understanding of teaching reform and the desire to improve self-ability. Therefore, such teachers should be given more opportunities to learn and exchange, so that they can go to the more successful institutions of statistical teaching reform to carry out curriculum reform learning, from the aspects of classroom content, classroom organization, assessment methods, case design, etc. moreover, it is possible to fully mobilize such leading teachers, prepare statistical textbooks suitable for use in the school, and update statistical cases in real time, in order to achieve long-term and effective educational reform results.

\subsection{Passively Accepted Teachers: Rational and Abstract}

In the teaching staff, some teachers believe that the education system does not need to change dramatically, but only needs some minor changes. Teachers in this category often passively accept the requirements of teaching reform in the reform, although they will also participate in the teaching reform, but they are not active. They believe that teaching reform is still a new thing, whether the reform is perfect, and how long the reform is over is an unanswerable question.

For such teachers, giving them a more specific understanding of the goals of education reform and the value they can achieve is the key to mobilizing their enthusiasm in the process of educational reform.

Therefore, in the teaching reform of statistics for economics and management majors, the successful cases of reform, the display of statistical classroom teaching methods of famous business schools, etc., can help such teachers to understand the standards of higher-level statistical classrooms to a certain extent, making them have clearer understanding of the final results and successful basis of the teaching reform, and thus more able to participate in the teaching reform with the goal of reform.

\section{3. "Unwilling to Accept and Disagree" Teacher: Emotional and Practical}

Some teachers believe that teaching needs reform and it needs to be reformed from its roots. This type of teacher has a clear 
and practical understanding of the teaching reform, but it is very emotional. They believe that the whole world is opposed to teaching. The media is always criticizing teachers. Teachers lack sufficient respect and trust. At the same time, they also clearly recognize the necessity of teaching reform and are willing to devote themselves to teaching reform.

General statistics teachers in undergraduate colleges and universities often lack enthusiasm for class because students are not interested in mathematics. Therefore, giving teachers enough trust and supporting them to do some teaching reforms that they think are correct may better mobilize their enthusiasm for teaching reform. At the same time, in the teaching process of statistics, increase the statistical cases related to the professional knowledge related to financial accounting (such as combining the sampling inference with the audit in the CPA exam), and quality management (such as the hypothesis test and the quality inspection of the enterprise), combined with statistical cases of relevant knowledge, etc., it may be possible to better mobilize the enthusiasm of students, so that such teachers get the students' likes and feelings. Therefore, in the process of promoting the reform of statistical teaching of economics and management, other full-time teachers in the management profession should also give a certain degree of support.

\subsection{Teachers Looking for Meaning and Faith: Emotional and Abstract}

The last category of teachers is in the emotional-abstract dimension. They believe that teaching needs reform, but the fundamental of reform is to improve the status of teachers. For the teaching reform, the reflection of this kind of teachers is very emotional and very unspecific. They think that the current teaching reform is meaningless. The final result of the reform is that the teachers become workers in the assembly line, and the students become goods on the assembly line. For this type of teachers, although they also believe that teaching needs reform, the purpose of reform is to start from their own interests. They believe that the standard of success in teaching reform is that society and schools are more friendly to teachers, and reform can help teachers.

Therefore, it is very difficult to promote teaching reform. For this type of teacher, appropriate incentives can be given to enable such teachers to benefit from successful teaching reforms. At the same time, the teaching reform of statistics should also be diversified. For example, students of different majors should set up different statistical courses with different emphasis, which makes the teaching of statistics more targeted, and the teaching of teachers is no longer unchanged.

\section{CONCLUSIONS}

By analyzing teachers' attitudes toward statistical teaching reform, teachers are divided into four different categories. Corresponding guidance suggestions were provided for each category of teachers. Increasing the proportion of practical courses, closely fitting to the reality, and classifying each type of teachers, etc., will help to improve teachers' enthusiasm for statistical teaching reform, thus ensuring the advancement of teaching reform.

\section{ACKNOWLEDGMENT}

This article is in the Teaching research project "the Foundation Course Construction Project for Aba Teachers University" No. 201803043.

\section{REFERENCES}

[1] Hinde E R. School culture and change: An examination of the effects of school culture on the process of change $[\mathrm{J}]$. Essays in Education, 2004, 12(3): 1-12.

[2] Fullan M. The future of educational change: System thinkers in action[J]. Journal of educational change, 2006, 7(3): 113-122.

[3] Raz A E, Fadlon J. Managerial culture, workplace culture and situated curricula in organizational learning $[\mathrm{J}]$. Organization Studies, 2006, 27(2): 165-182.

[4] Thomas L, Beauchamp C. Understanding new teachers' professional identities through metaphor[J]. Teaching and teacher Education, 2011, 27(4): 762-769.

[5] DAI L, ZHENG X. Research on the Reform and Practice of Teaching Mode in Colleges and Universities under the Background of Artificial Intelligence-A Case Study of Statistical Curriculum[J]. DEStech Transactions on Social Science, Education and Human Science, 2019 (icesd).

[6] Ben-Zvi D, Gravemeijer K, Ainley J. Design of statistics learning environments[M]//International handbook of research in statistics education. Springer, Cham, 2018: 473502.

[7] Fullan M. Choosing the wrong drivers for whole system reform $[\mathrm{M}]$. Melbourne: Centre for Strategic Education, 2011:3-4.

[8] Harris R, Graham S. Engaging with curriculum reform: insights from English history teachers' willingness to support curriculum change[J]. Journal of Curriculum Studies, 2019, 51(1): 43-61.

[9] Ungar O A. Understanding teachers' attitude toward educational reforms through metaphors[J]. International Journal of Educational Research, 2016, 77: 117-127. 